\title{
Brief Biography of Professor Natale D'Alessandro Dedicated in His Memory
}

This Special Issue is in memory of Professor Natale (Nanni) D'Alessandro and it is a loving tribute to his scientific path. We feel particularly honored and excited to guest edit this Special Issue in Critical Reviews $^{\mathrm{TM}}$ in Oncogenesis because Nanni was not only a colleague and teacher, but also a dear friend for those of us who knew him.

Nanni was born in Palermo, Sicily, Italy, on September 18, 1946, and he graduated in Medicine at the University of Palermo in 1970 with a dissertation on the experimental thesis on the "Pharmacology of Adriamycin" for which he was awarded the excellent "A. Albanese" degree award. In 1975, he obtained the specialization in Clinical Hematology at the University of Modena. His academic career started immediately after obtaining his degree. From 1970 to 1983 he was Assistant Professor of Pharmacology and Associate Professor of Clinical Pharmacology (1983-1987) at the Institute of Pharmacology, University of Palermo Medical School, and in 1983 he was granted the title of Associate Professor in Clinical Pharmacology and Full Professor of Pharmacology (1990-1993) at the Institute of Pharmacocolgy, University of Messina Medical School. He worked in the Clinical Oncology section from 1976 to 1987 and in the Clinical Pharmacology Service, responsible for the U.O.C. of Clinical Pharmacology of the A.O.U.P. "P. Giaccone" of Palermo. He was Head of the Advisory Center on ADR in tumors in the Sicily Region since 2003 and member of numerous ethics committees.

He directed the Department of Pharmacological Sciences "P. Benigno" (2007-2010) and that of Sciences for Health Promotion "G. D'Alessandro" of the University of Palermo. He established and was Coordinator of the Doctorate in Pharmacology and Socio-Environmental Toxicology of the University of Palermo from 2001 to 2011.

During his career, he taught Pharmacology and degree courses in Medicine and Surgery, Dentistry and Dental Prosthetics, Prevention Technicians in the Environment and in the Workplaces, Dental Hygiene and Biomedicine, in multiple Schools of Specialization and I and II level Masters.

An important step of his carrier was the attendance in 1986 at the Institutes Gustave-Russy and ICIG in Villejuif where he worked with Dr. J.P. Armand and H. Tapiero. During this stage, he performed studies on the clinical pharmacology of aclacinomycin and cancer drug resistance. His research interests have covered the clinical and preclinical pharmacology of cancer, in particular the pharmacology and toxicology of the anthracyclines, clinical studies on drug therapies and pharmacokinetics, steroid hormone receptors, free radicals and the interrelationship between biological factors and multidrug resistance, development of new anticancer drugs (also of natural compounds), and also pharmacovigilance with particular reference to adverse reactions from antineoplastic drugs. In addition, his scientific achievements include various articles and reviews concerning aspects of general pharmacology, drug interactions, the pharmacoeconomics and pharmacogenetics of immunosuppressants and anticancer drugs, substances of abuse, and antimicrobial drugs. He was responsible for numerous research projects and was the author of more than 150 publications that continue to be cited today. His scientific versatility made him a critical and analytical researcher. Interestingly, his collaborations were not limited to the local audience of colleagues, but he built a research network that involved researchers from all over the world. His characteristic humanity and communication skills made these collaborative relationships into honest, sincere friendships. The presence of so many contributors who responded with enthusiasm to the realization of this special issue dedicated to him confirms his unique personality.

We remember with pleasure and nostalgia his participation in international congresses, such as in Crete, which became not only a moment of advanced scientific training but also of human 
communication, or the congresses of the Italian Society of Pharmacology and Chemotherapy of which he was a member and which he always attended with great enthusiasm. The fusion of science and friendship was a gift that he transmitted to us and that we carry with us with gratitude.

$\mathrm{He}$ directed and organized three international courses on cancer pharmacology at the E. Majorana Center in Erice (see Fig. 1): the NATO Advance Study Institute Specific Approaches in Cancer Therapy; Differentiation, Immunomodulation and Angiogenesis (1992); Genetic and Immunochemotherapeutic Approaches in Cancer Treatment (1996);

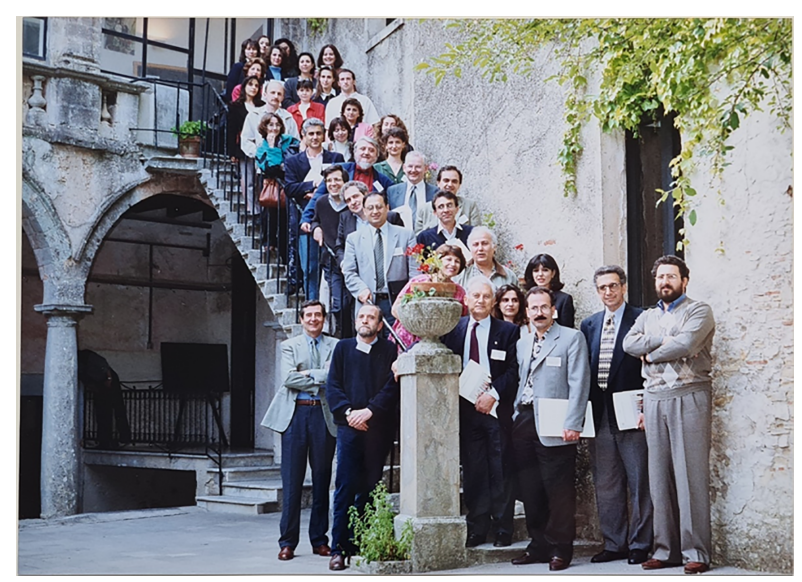

FIG. 1: International courses on cancer pharmacology at the E. Majorana Center in Erice: Genetic and immunochemotherapeutic approaches in cancer treatment (1996) and Angiogenesis and Signal Transduction in Anticancer Drug Development (2001). Nanni was a charismatic teacher for young researchers and he created his research group, which today works at the Department of Biological, Chemical and Pharmaceutical Science and Technology, University of Palermo, pursuing the theme and research style learned from him.

His research team is deeply grateful for all he has taught them and for giving them the opportunity to work with him and to see the enthusiasm of the colleagues who have known Nanni. This confirms that the esteem and affection of the people who collaborated with him are still alive.

Finally, we want to dedicate two quotes from Albert Einstein and Luigi Pirandello that befit his personality:

"I have no special talents. I am only passionately curious.” A. Einstein

"It is much easier to be a hero than a gentleman. Heroes can be once in a while; gentlemen, it must always be." (È molto più facile essere un eroe che un galantuomo. Eroi si può essere una volta tanto; galantuomini, si deve essere sempre.) Luigi Pirandello, "Il piacere dell'onesta."

Thanks, Nanni, for everything you have given us.

Monica Notarbartolo and Marina Ziche 